\title{
The uniaxial compressive strength of fiber-reinforced frozen backfill
}

\author{
Huiya Niu \\ State Key Laboratory of Geomechanics \& Deep Underground Engineering, China University of Mining \& \\ Technology, Beijing, China \\ Ferri P. Hassani \& Mehrdad F. Kermani \\ Mining Engineering Department, McGill University \\ Manchao He \\ State Key Laboratory of Geomechanics \& Deep Underground Engineering, China University of Mining \& \\ Technology, Beijing, China
}

\begin{abstract}
The possible application of using fiber-reinforced frozen $\left(-15^{\circ} \mathrm{C}\right)$ mine backfill was investigated using a series of laboratory experiments. Sisal fiber, Basalt fiber, and Biofilament were added to the tailings and water that constituted primary backfill, which served as the reference material. Samples differed in terms of fiber type, fiber content, and curing temperature. The mechanical properties of samples were investigated using the uniaxial compression strength (UCS) test. The UCS of fiber-reinforced frozen backfill exceeded that of primary backfill and reached as high as $5.95 \mathrm{MPa}$. The UCS stress-strain behavior of mine backfill was markedly affected by freezing and fiber addition. Frozen backfill exhibited more ductile behavior and a higher elasticity modulus than unfrozen backfill, which showed brittle behavior. Fiber-reinforced backfill could absorb more energy before total failure.
\end{abstract}

Keywords: Sisal fiber, Basalt fiber, Bio-filament, fiber-reinforced backfill, frozen backfill, uniaxial compressive strength

\section{INTRODUCTION}

The practice of filling the void created by underground mining activities with waste materials is termed mine backfilling and is generally an integral part of the underground mining process. Mine backfill is mainly used to increase ore extraction and underground mine stabilization and to reduce the volume of deposited waste materials. Mine backfill mostly comprises tailings (waste), water, and binders - usually Portland cement (PC) (Weaver \& Luka 1970; Benzaazoua et al. 2004b; Wang \& Qiao 2019). PC accounts for up to $75 \%$ of the cost of mine backfill (Hassani \& Bois 1989; Potvin et al. 2005; Li et al. 2019), and PC production contributes a large amount of carbon dioxide to the atmosphere. Furthermore, increased demand for minerals and depletion of more accessible minerals forces mining companies to expand operations to more remote areas (e.g., higher latitudes in Canada). These challenges require innovative methods to meet the requirements of a mining operation in an environmentally friendly manner. Thus, exploring alternative binders to fully or partially replace PC to reduce the cost and carbon footprint (as well as improve the mechanical strength) of mine backfill has been 
the focus of several research projects (Benzaazoua et al. 2004a; Kesimal et al. 2005; Mohamed Abdel-Mohsen et al. 2007; Singh et al. 2019).

Examples of alternative binders are pozzolanic products (Ercikdi et al. 2010), fly ash, and slag (Bouzoubaa \& Foo 2004). Samples containing fly ash exhibited higher uniaxial compressive strength (UCS) than samples containing PC (Hassani et al. 2007). Cemented paste backfill (CPB) containing a mixture of fly ash $(40 \%)$ and PC $(60 \%)$ showed improved sulphate resistance (Benzaazoua et al. 1999). Among paste backfill samples prepared with PC, fly ash, and slag, slag-based samples had higher triaxial compressive strength (Belem et al. 2000). Other important factors affecting the physical properties of CPB are tailings properties (Kesimal et al. 2004; Fall et al. 2005; Kesimal et al. 2005), binder types and dosage (Kesimal et al. 2004; Ercikdi et al. 2009; Ercikdi et al. 2014), curing time (Yilmaz et al. 2015), and other additives (Mitchell \& Stone 1987; Kermani et al. 2015; Koohestani et al. 2016; Mangane et al. 2018).

In cold and remote environments, application and transportation of cementitious materials are costly and logistically challenging. For instance, the hydration of cementitious material can dramatically decelerate or even cease in cold ambient temperatures (Jiang et al. 2020). Limited research has explored the feasibility of using ice as the main cementitious agent in mine backfill in cold climates. Although this method appeared to be feasible in terms of meeting strength and stiffness requirements, the cost of frozen backfill was low compared to conventional backfill (Daniel \& Kazakidis 2012). Han (2011) compared the performance of frozen tailings backfill, with mechanical properties strongly influenced by water content, tailings fineness, and compaction pressure, to that of frozen cemented paste backfill with mechanical properties significantly affected by cement content, curing age, and binder type. The frozen tailings backfill displayed strain softening behaviors and a relatively brittle failure mode, whereas the frozen cemented paste backfill displayed strain hardening behaviors and was ductile.

Given the strength limitations of frozen backfill noted in previous studies, the aim of this work is to investigate the effect on the UCS and deformation behavior of reinforcing frozen backfill with Sisal fiber, Basalt fiber, and Bio-filament. An orthogonal experiment design was used to study the effect of fiber type, fiber content, and curing temperature. This study is expected to provide a reference to evaluate the performance of fiber-reinforced frozen backfill and help reduce the usage of $\mathrm{PC}$ in mine backfill.

\section{MATERIALS}

\subsection{Tailings}

Tailings were obtained from a mine in northern Quebec, Canada. The specific gravity $\left(G_{s}\right)$, particle size $\left(D_{i}\right.$ where $\mathrm{i}=10,30,50,60$, and $\left.90 \mathrm{~mm}\right)$, and coefficients of uniformity $\left(C_{u}\right)$ and curvature $\left(C_{c}\right)$ are summarized in Table 1 . Figure 1 shows the particle size distribution of tailings, which were tested in according to ASTM C136/C136M-14 (2014). Table 2 lists the chemical composition analyzed by X-ray fluorescence.

\subsection{Binder}

Both primary and fiber-reinforced samples were made with $0 \%$ and $2 \%$ (dry mass of solid materials) General Use Type 10 Portland cement as binder.

Table 1. Physical properties of Westwood tailings.

\begin{tabular}{llllllll}
\hline$G_{s}\left(\mathrm{~g} / \mathrm{cm}^{3}\right)$ & $D_{10}(\mu \mathrm{m})$ & $D_{30}(\mu \mathrm{m})$ & $D_{50}(\mu \mathrm{m})$ & $D_{60}(\mu \mathrm{m})$ & $D_{90}(\mu \mathrm{m})$ & $C_{u}$ & $C_{c}$ \\
\hline 2.93 & 3.95 & 8.6 & 12.1 & 14.0 & 23.0 & 3.5 & 1.3 \\
\hline
\end{tabular}




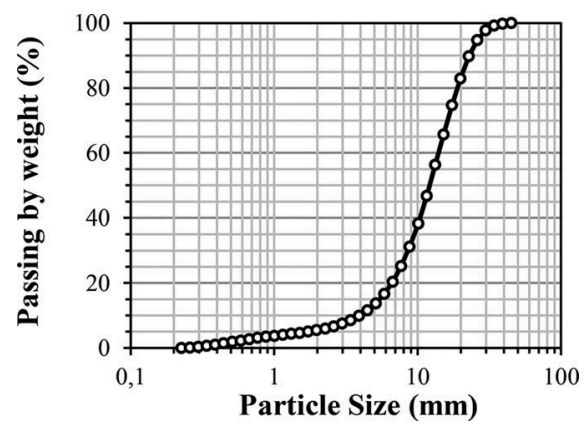

Figure 1. Particle size distribution of tailings.

Table 2. Chemical composition of Westwood tailings.

\begin{tabular}{lllllllll}
\hline Oxides & $\mathrm{SiO}_{2}$ & $\mathrm{Al}_{2} \mathrm{O}_{3}$ & $\mathrm{Fe}_{2} \mathrm{O}_{3}$ & $\mathrm{SO}_{3}$ & $\mathrm{CaO}$ & $\mathrm{MgO}$ & $\mathrm{K}_{2} \mathrm{O}$ & $\mathrm{Na}_{2} \mathrm{O}$ \\
\hline Content (\%) & 49.02 & 17.67 & 9.15 & 7.29 & 6.52 & 3.97 & 2.70 & 1.50 \\
Metal element & $\mathrm{P}$ & $\mathrm{Ni}$ & $\mathrm{Cu}$ & $\mathrm{Cl}$ & $\mathrm{Cr}$ & $\mathrm{Zr}$ & $\mathrm{Sr}$ & $\mathrm{Rb}$ \\
Content (ppm) & 677 & 648 & 406 & 319 & 115 & 108 & 90 & 44 \\
\hline
\end{tabular}

\subsection{Fiber}

Sisal fiber (Figure 2) is extracted from the Sisal plant and has the advantages of high strength, easy processing, good dispersion, and low cost. The tensile strength and Young's modulus (Table 3) are mostly influenced by filament diameter and length (Deák \& Czigány 2009; Jiang et al. 2014). Basalt fiber (Figure 2) is melted at $1450-1500^{\circ} \mathrm{C}$ and drawn through a platinum-rhodium alloy plate at a high speed, giving it high strength, electrical insulation, corrosion resistance, high

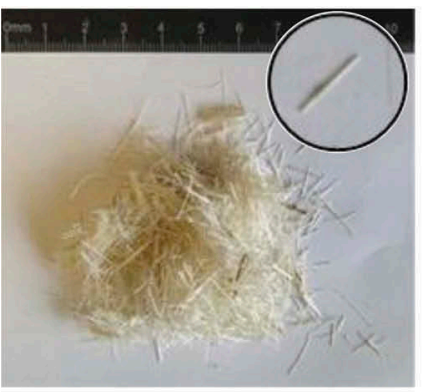

Sisal fiber

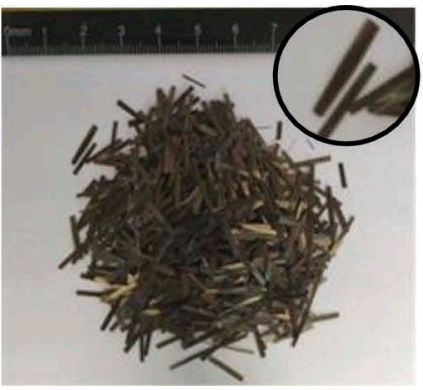

Basalt fiber

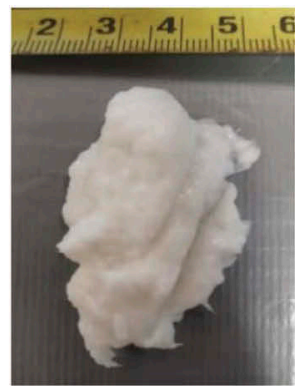

Bio-filament

Figure 2. Photographs of Sisal fiber, Basalt fiber, and Bio-filament.

Table 3. Physical properties of Sisal and Basalt fiber.

\begin{tabular}{lllll}
\hline $\begin{array}{l}\text { Fiber } \\
\text { type }\end{array}$ & $\begin{array}{l}\text { Young's modulus } \\
(\mathrm{GPa})\end{array}$ & $\begin{array}{l}\text { Tensile strength } \\
(\mathrm{MPa})\end{array}$ & $\begin{array}{l}\text { Filament length } \\
(\mathrm{mm})\end{array}$ & $\begin{array}{l}\text { Filament diameter } \\
(\mu \mathrm{m})\end{array}$ \\
\hline Sisal & $9-26$ & $5500-6500$ & 10 & $300-500$ \\
Basalt & $28-110$ & $400-4800$ & 10 & $7-15$ \\
\hline
\end{tabular}

Soure: Tolêdo Filho et al. (2000); Ku et al. (2011); Ratna Prasad and Mohana Rao (2011); Alves Fidelis et al. (2013); Ramesh et al. (2013); Sultan (2005);Deák and Czigány (2009); Lopresto et al. (2011); Colombo et al. (2012); Jiang et al. (2014). 
temperature resistance, and degradability. The tensile strength is lower for short than continuous Basalt fibers (Table 3). The Bio-filament was supplied by Performance Bio-filaments Inc., who produce cellulose filaments from wood pulp. The process results in cellulose filaments of exceptional strength and purity, with an extraordinary high and unique aspect ratio. Bio-filament is a "wet fluff" (Figure 2) with 4\% solid content and is dispersible in solvents like water.

\section{SAMPLE PREPARATION AND EXPERIMENT SETUP}

Fourteen batches of mine backfill samples were prepared with a solids concentration of $70 \%$ (Table 4). The fiber contents of the fiber-reinforced samples were 0.5 and $1.0 \mathrm{wt} \%$. Reference samples contained no fiber.

To prepare the samples, dry materials were weighed and mixed for 2 min using a mixer with a stainless-steel wire whip blade. Water was added gradually and mixed for another 5 min. Cylindrical molds (100 $\mathrm{mm}$ deep and $50 \mathrm{~mm}$ diameter) were used to cast the specimens. Specimens containing $2 \mathrm{wt} \%$ of the binder PC (Group 1 in Table 4) were cured in a curing chamber where the relative humidity was kept constant at $(90 \pm 2 \%)$ and the temperature was adjusted to $\left(20 \pm 1^{\circ} \mathrm{C}\right)$ for 3 days and then moved to a freezer where the temperature was kept constant at $-15^{\circ} \mathrm{C}$. Samples without any binder (Group 2) were cured directly in a freezer at $-15^{\circ} \mathrm{C}$. Moreover, unfrozen samples in Group 2 were prepared and dried at ambient temperature $\left(+20^{\circ} \mathrm{C}\right)$ for comparison to frozen samples.

The unfrozen samples in Group 2 was not consolidated until 50 days later. The UCS test was conducted after 56 days of curing to evaluate the mechanical properties of specimens according to ASTM C39/C39M-18 (2018). To minimize the influence of heat exchange between the specimen and the ambient environment on the UCS results of frozen backfill, the upper and lower plate of test device was also frozen at the same temperature as the samples.

\section{RESULTS AND DISCUSSION}

\subsection{Reinforced effect of fibers on unfrozen dry and frozen backfill samples}

Adding fiber to specimens dried and cured at $+20^{\circ} \mathrm{C}$ did not affect the UCS (Figure 3). However, freezing all Group 2 specimens lacking PC binder (with or without fiber) enhanced the

Table 4. Experimental design.

\begin{tabular}{|c|c|c|c|c|c|}
\hline \multirow[b]{2}{*}{ Sample } & \multicolumn{2}{|l|}{ Fiber } & \multirow[b]{2}{*}{$\begin{array}{l}\text { Binder } \\
\left(\mathrm{wt}^{\circ} \%\right)\end{array}$} & \multirow[b]{2}{*}{$\begin{array}{l}\text { Dry tailings } \\
\left(\mathrm{wt}^{\%} \%\right)\end{array}$} & \multirow[b]{2}{*}{ Curing condition } \\
\hline & Type & $\begin{array}{l}\text { Content } \\
\left(\mathrm{wt}^{0} \%\right)\end{array}$ & & & \\
\hline 1 & None & 0 & 2 & 98.0 & \multirow{7}{*}{$\begin{array}{l}\text { Group 1: cured for } 3 \text { days at } 20^{\circ} \mathrm{C} \text { and then } \\
\text { frozen at }-15^{\circ} \mathrm{C} \text {. }\end{array}$} \\
\hline 2 & Sisal & 0.5 & 2 & 97.5 & \\
\hline 3 & Sisal & 1.0 & 2 & 97.0 & \\
\hline 4 & Basalt & 0.5 & 2 & 97.5 & \\
\hline 5 & Basalt & 1.0 & 2 & 97.0 & \\
\hline 6 & Bio & 0.5 & 2 & 97.5 & \\
\hline 7 & Bio & 1.0 & 2 & 97.0 & \\
\hline 8 & None & 0 & 0 & 100 & \multirow{5}{*}{$\begin{array}{l}\text { Group 2: frozen: cured at }-15^{\circ} \mathrm{C} \text {. } \\
\text { Group 2: unfrozen: }\end{array}$} \\
\hline 9 & Sisal & 0.5 & 0 & 99.5 & \\
\hline 10 & Sisal & 1.0 & 0 & 99.0 & \\
\hline 11 & Basalt & 0.5 & 0 & 99.5 & \\
\hline 12 & Basalt & 1.0 & 0 & 99.0 & \\
\hline 13 & Bio & 0.5 & 0 & 99.5 & \multirow[t]{2}{*}{ Dried and cured at $+20^{\circ} \mathrm{C}$. } \\
\hline 14 & Bio & 1.0 & 0 & 99.0 & \\
\hline
\end{tabular}




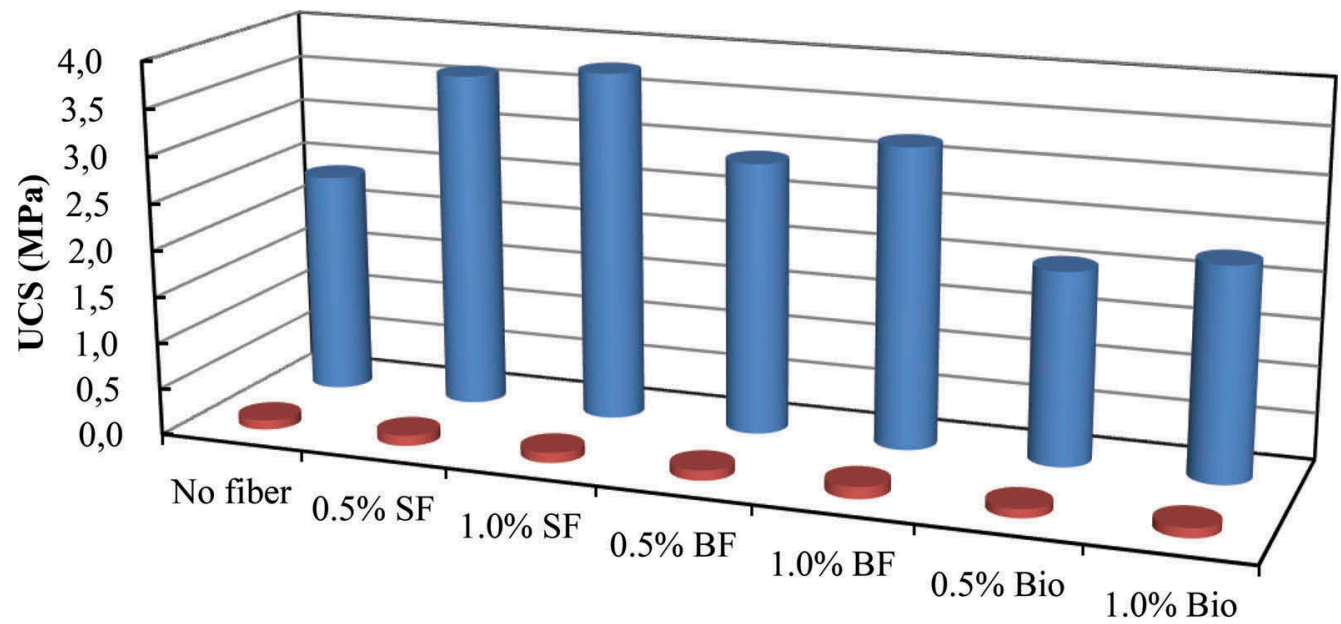

\section{Natural dry $\square$ Frozen samples}

Figure 3. UCS of unfrozen and frozen dried backfill samples without and with reinforcement with Basalt fiber (BF), Sisal fiber (SF), and Bio-filaments (Bio).

UCS: Sisal fiber was associated with the highest UCS (3.76 MPa), whereas Bio-filament addition resulted in lower UCS than the no fiber treatment. For a given fiber type, the UCS of frozen specimens was higher at $1 \%$ then $0.5 \%$ fiber concentration. This indicates that the bond between ice and fibers formed after the phase transition from water to the crystalline ice.

After 56 days of freezing, the UCS of fiber-reinforced frozen backfill specimens containing $2 \mathrm{wt} \%$ PC (Group 1 in Table 4) was 43\% (Sisal fiber) to $143 \%$ (Biofilament) higher than the UCS of specimens lacking PC (Figure 4). In the presence of PC, the fiber content (0.5 vs. $1.0 \%$ ) did not affect the UCS as much as it did when PC was absent. This phenomenon can be attributed to the hydration of cement, the phase transition of water, and enhanced bond integration between tailings particles and fibers.

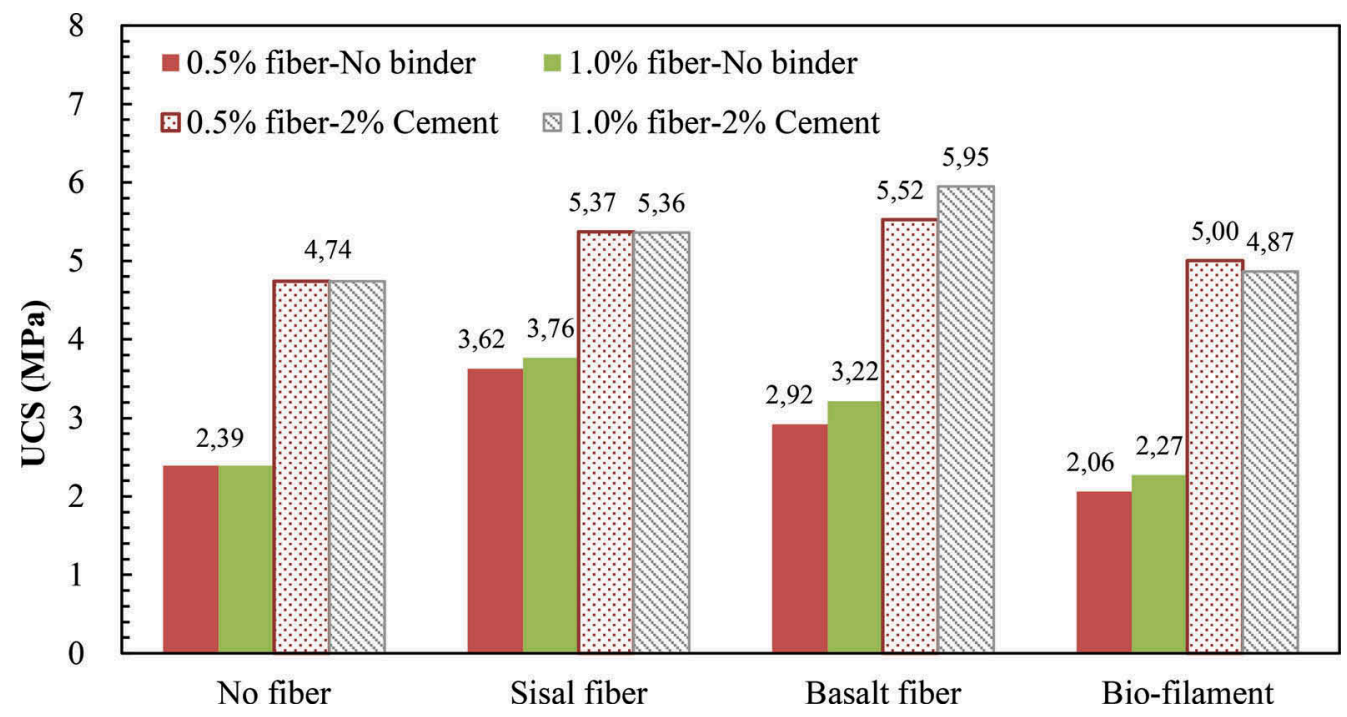

Figure 4. UCS of frozen backfill samples with and without binder cement. 
The increase in UCS of backfill as result of inclusion of fiber reinforcement can be expressed as the UCS improvement factor, $I_{R}$, defined as:

$$
I_{R}=\frac{\sigma_{R}-\sigma_{U}}{\sigma_{U}}
$$

Where $\sigma_{R}$ is the UCS of fiber-reinforced backfill and $\sigma_{U}$ is the UCS of unreinforced backfill. The $I_{R}$ represents the relative gain in UCS of backfill due to the addition of fiber. Table 5 presents the $I_{R}$ of frozen backfill without and with PC, using $\sigma_{U}$ values of 2.39 and $4.74 \mathrm{MPa}$, respectively (Figure 4).

\subsection{Deformation behavior of fiber-reinforced}

The UCS stress-strain behavior of mine backfill was markedly affected by freezing (Figure 5). Frozen backfill not only obtained higher UCS values, but also exhibited more ductile behaviors and higher elasticity modulus, while the unfrozen backfill shows brittle behavior. The fiber-reinforced backfill is able to hold together for more deformation and therefore higher strength at failure. Therefore, the fiber-reinforced backfill can absorb more energy before total failure.

The brittle behavior of unfrozen tailings backfill (Figure 6) was transformed by freezing to a more ductile behavior (Figure 7). Unreinforced backfill samples failed at a relative low axial strain (approximately 2.4\%), whereas backfill samples reinforced with Basalt fiber failed at approximately $3.3 \%$ axial strain and those reinforced with Sisal fiber failed at approximately

Table 5. Improvement factor, $I_{R}$, of frozen fiber-reinforced backfill.

\begin{tabular}{llll}
\hline No Cement & & $2 \%$ Cement & \\
\hline Fiber & $I_{R}(\%)$ & Fiber & $I_{R}(\%)$ \\
\hline $0.5 \%$ Sisal & 51.38 & $0.5 \%$ Sisal fiber & 13.28 \\
$1.0 \%$ Sisal & 57.13 & $1.0 \%$ Sisal fiber & 13.03 \\
$0.5 \%$ Basalt & 22.02 & $0.5 \%$ Basalt fiber & 16.51 \\
$1.0 \%$ Basalt & 34.36 & $1.0 \%$ Basalt fiber & 25.43 \\
$0.5 \%$ Bio-filament & -13.83 & $0.5 \%$ Bio-filament & 5.52 \\
$1.0 \%$ Bio-filament & -5.11 & $1.0 \%$ Bio-filament & 2.63 \\
\hline
\end{tabular}

(a)

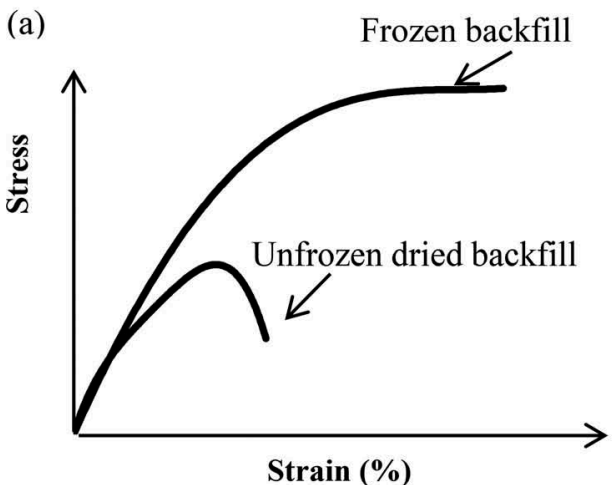

(b)

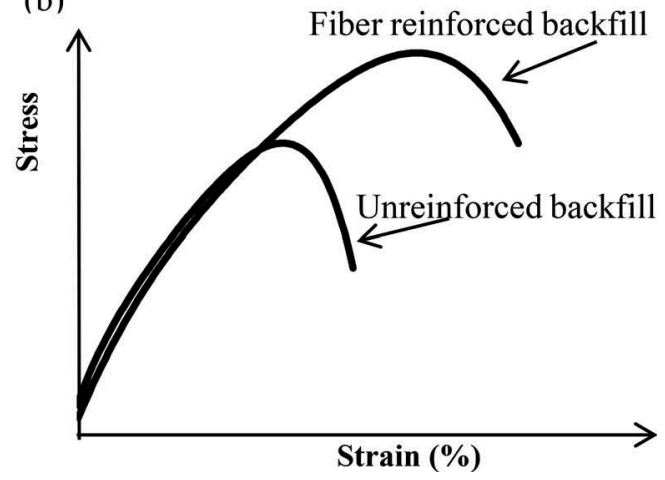

Figure 5. Typical unconfined compressive stress-strain curves for (a) unfrozen dried and frozen backfill; (b) unreinforced and fiber-reinforced backfill. 
$3.7 \%$ (Figure 6). The higher fiber content seems improve the UCS and elasticity modulus, but does not contribute to the ductility of unfrozen dried backfill.

The stress of frozen specimens rose faster than that of specimens dried without freezing during the elastic deformation stage (Figure 7). Fibers contributed to elevated UCS while the fiber content dominated the post-peak behavior. Among the three fibers, Sisal fiber had the strongest influence and Bio-filament had the weakest influence on the ductile behavior of backfill. The bond between tailings and fiber contributed to the enhanced ductility. All tests on reinforced specimens exhibited strain-hardening behavior with increasing strength as the strain increased.

The $E_{50}$, deformation energy, and post-peak strength of typical frozen samples were considered as indices to evaluate the performance of frozen backfill, in addition to UCS. $E_{50}$ is the secant modulus at $50 \%$ UCS and is considered the elastic index. The energy absorbed by a unit volume of backfill before peak strength is calculated by:

$$
M_{0}=\int \sigma d \varepsilon
$$

$M_{0 \mathrm{P}}$ is the other index to evaluate the performance of frozen backfill:

$$
M_{0 P}=\int_{0}^{\sigma_{0}} \sigma d \varepsilon
$$

Where $\sigma_{0}$ is the peak strength of backfill.

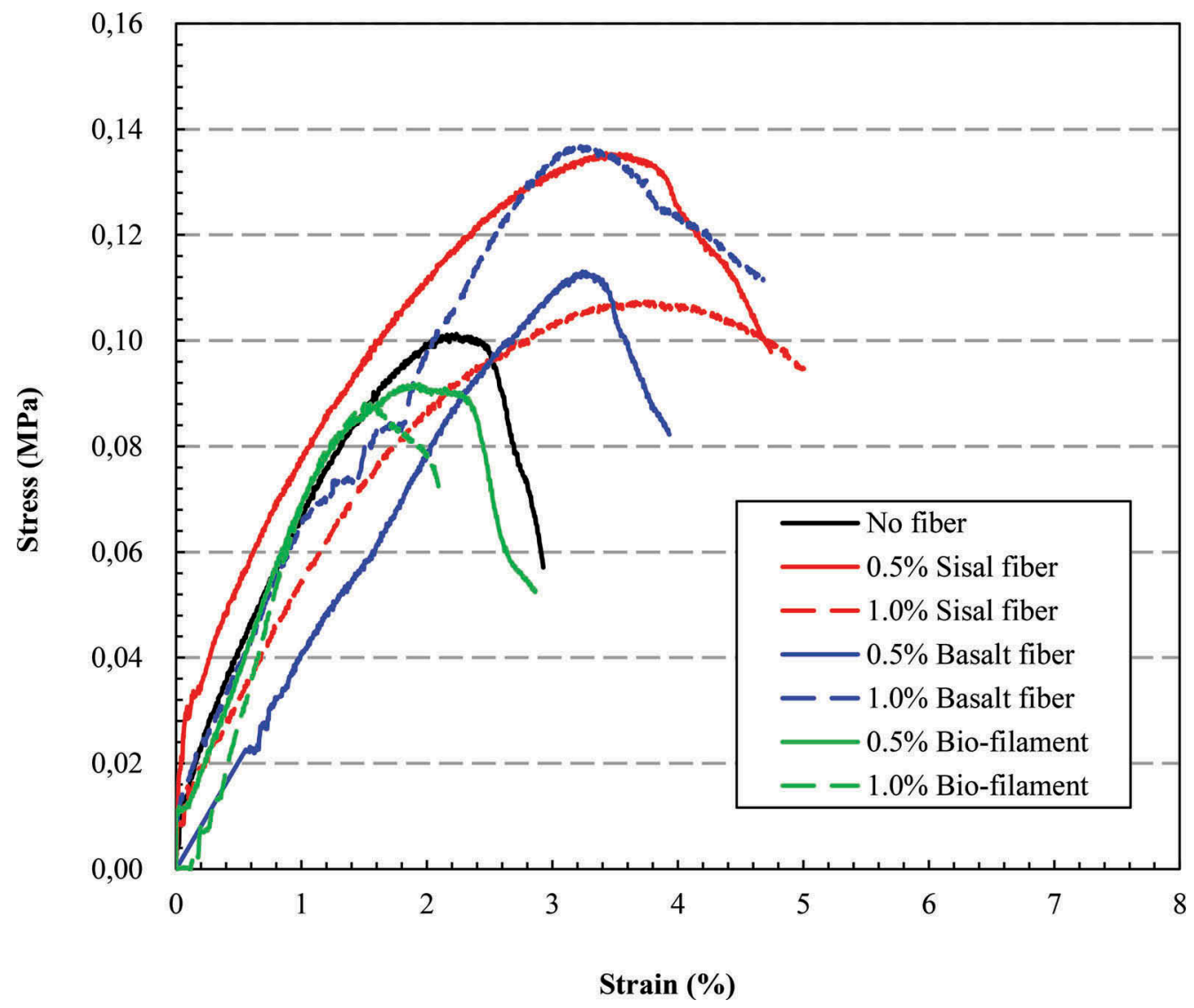

Figure 6. Typical stress-strain curves for unfrozen dry backfill samples without binder cement. 

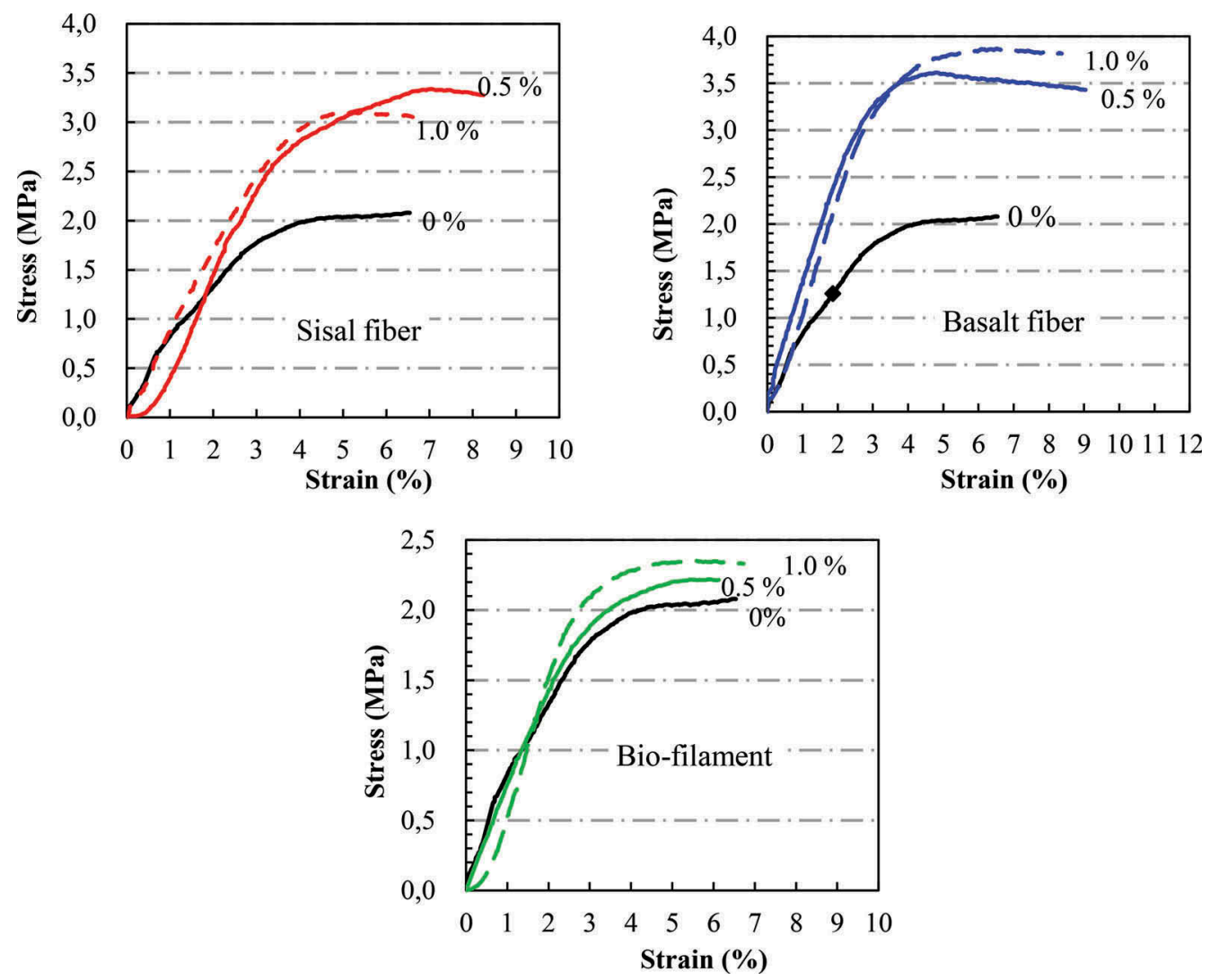

Figure 7. Typical stress-strain curves of frozen backfill samples without binder cement.

From Table 6, the fiber-reinforced frozen backfill absorbed more energy. The addition of Sisal and Basalt and fiber enhanced the UCS and residual strength, and improved the initial stiffness. The contribution of Bio-filament to frozen backfill performance was not significant.

Table 6. Strength performance of frozen fiber-reinforced backfill.

\begin{tabular}{llll}
\hline Frozen backfill type & $E_{50}(\mathrm{MPa})$ & $\begin{array}{l}\text { Energy absorbed before } \\
\text { failure, } M_{0 P}(\mathrm{~kJ})\end{array}$ & Post-peak strength (MPa) \\
\hline No fiber & 0.74 & 71.4 & 2 \\
$0.5 \%$ Basalt fiber & 1.24 & 117.84 & 3.42 \\
1.0\% Basalt fiber & 1.14 & 184.81 & 3.81 \\
$0.5 \%$ Sisal fiber & 1.02 & 147.61 & 3.27 \\
$1.0 \%$ Sisal fiber & 0.87 & 96.16 & 3.05 \\
$0.5 \%$ Bio-filament & 0.73 & 105.53 & 2.19 \\
$1.0 \%$ Bio-filament & 1.02 & 86.97 & 2.33 \\
\hline
\end{tabular}




\section{CONCLUSION}

A series of experiments explored potential application of frozen backfill with or without fiber (Sisal, Basalt, and Bio-filament) reinforcement as an alternative to CPB. The highest UCS $(5.95 \mathrm{MPa}$ ) was achieved with frozen backfill containing 2\% PC and 1\% Basalt fiber. Freezing transformed the deformation behavior of backfill from brittle to more ductile. The fiberreinforced frozen backfill absorbed more energy. Sisal and Basalt fiber addition not only enhanced the UCS and residual strength but also improved the initial stiffness. The contribution of Bio-filament to frozen backfill strength was not significant.

\section{ACKNOWLEDGEMENTS}

This work was supported by Geomechanics Laboratory in McGill University and Iamgold Inc. . Comments by Janice Burke improved an earlier version of the paper.

\section{BIBLIOGRAPHY}

Alves Fidelis et al. 2013. The effect of fiber morphology on the tensile strength of natural fibers. Journal of Materials Research and Technology, 2(2), pp. 149-157.

Belem et al. 2000. Mechanical behaviour of cemented paste backfill. Proceedings of 53th.

Benzaazoua et al. 1999. Cementitious backfill with high sulfur content physical, chemical, and mineralogical characterization. Cement and Concrete Research, 29(5), pp. 719-725.

Benzaazoua et al. 2004a. A contribution to understanding the hardening process of cemented pastefill. Minerals Engineering - MINER ENG, 17.

Benzaazoua et al. 2004b. The use of pastefill as a solidification and stabilization process for the control of acid mine drainage. Minerals Engineering, 17(2), pp. 233-243.

Bouzoubaa and Foo. 2004. Use of fly ash and slag in concrete: A best practice guide. Materials and Technology Laboratory, MTL, 16.

ASTM C39/C39M-18. 2018. Standard test method for compressive strength of cylindrical concrete specimens. West Conshohocken, PA: ASTM International.

ASTM C136/C136M-14. 2014. Standard test method for sieve analysis of fine and coarse aggregates. West Conshohocken, PA: ASTM International.

Colombo et al. 2012. Static and fatigue characterisation of new basalt fibre reinforced composites. Composite Structures, 94(3), pp. 1165-1174.

Deák and Czigány. 2009. Chemical composition and mechanical properties of basalt and glass fibers: A comparison. Textile Research Journal, 79(7), pp. 645-651.

Ercikdi et al. 2009. Cemented paste backfill of sulphide-rich tailings: Importance of binder type and dosage. Cement and Concrete Composites, 31(4), pp. 268-274.

Ercikdi et al. 2010. Effect of natural pozzolans as mineral admixture on the performance of cemented-paste backfill of sulphide-rich tailings. Waste Management \& Research, 28(5), pp. 430-435.

Ercikdi et al. 2014. Strength and ultrasonic properties of cemented paste backfill. Ultrasonics, 54(1), pp. 195-204.

Fall et al. 2005. Experimental characterization of the influence of tailings fineness and density on the quality of cemented paste backfill. Minerals engineering, 18(1), pp. 41-44.

Han 2011. Geotechnical behaviour of frozen mine backfills. Master degre, University of Ottawa.

Hassani and Bois. 1989. Economic and technical feasibility for backfill design in quebec underground mines. Final report 1/2, canada-quebec mineral development agreement. Research and Development in Quebec Mines. Contract No. EADM, 1992.

Hassani et al. 2007. Physical and mechanical behavior of various combinations of mine fills materials. CIM Bulletin, 100(3), pp. 1-6.

Jiang et al. 2014. Experimental study on the mechanical properties and microstructure of chopped basalt fibre reinforced concrete. Materials \& Design, 58.pp 187-193.

Jiang et al. 2020. Ultrasonic evaluation of strength properties of cemented paste backfill: Effects of mineral admixture and curing temperature. Ultrasonics, 100. pp. 105983.

Kermani et al. 2015. Evaluation of the effect of sodium silicate addition to mine backfill, gelfill - part 1 . Journal of Rock Mechanics and Geotechnical Engineering, 7(3), pp. 266-272. 
Kesimal et al. 2004. Evaluation of paste backfill mixtures consisting of sulphide-rich mill tailings and varying cement contents. Cement and concrete research, 34(10), pp. 1817-1822.

Kesimal et al. 2005. Effect of properties of tailings and binder on the short-and long-term strength and stability of cemented paste backfill. Materials Letters, 59(28), pp. 3703-3709.

Koohestani et al. 2016. Experimental investigation into the compressive strength development of cemented paste backfill containing nano-silica. Cement and Concrete Composites, 72. pp. 180-189.

$\mathrm{Ku}$ et al. 2011. A review on the tensile properties of natural fiber reinforced polymer composites. Composites Part B: Engineering, 42(4), pp. 856-873.

$\mathrm{Li}$ et al. 2019. Evaluation of short-term strength development of cemented backfill with varying sulphide contents and the use of additives. Journal of Environmental Management, 239. pp. 279-286.

Lopresto et al. 2011. Mechanical characterisation of basalt fibre reinforced plastic. Composites Part B: Engineering, 42(4), pp. 717-723.

Mangane et al. 2018. Influence of superplasticizers on mechanical properties and workability of cemented paste backfill. Minerals Engineering, 116.pp. 3-14.

Mitchell and Stone. 1987. Stability of reinforced cemented backfills. canadian geotechnical journal, 24(2), pp. 189-197.

Mohamed Abdel-Mohsen et al. 2007. Evaluation of newly developed aluminum, lime, and fly ash technology for solidifaction/stabilization of mine tailings. Journal of Materials in Civil Engineering, 19(1), pp. $105-111$.

Potvin et al. 2005. Handbook on mine fill. Crawley, WA, Australia: Australian Centre for Geomechanics.

Ramesh et al. 2013. Mechanical property evaluation of sisal-jute-glass fiber reinforced polyester composites. Composites Part B: Engineering, 48. pp. 1-9.

Ratna Prasad and Mohana Rao. 2011. Mechanical properties of natural fibre reinforced polyester composites: Jowar, sisal and bamboo. Materials \& Design, 32(8), pp. 4658-4663.

Singh et al. 2019. Optimisation of binder alternative for cemented paste fill in underground metal mines. Arabian Journal of Geosciences, $\mathbf{1 2}(\mathbf{1 5 0}$ pp. 462.

Sultan. 2005. The effect of fibre content on the mechanical properties of hemp and basalt fibre reinforced phenol formaldehyde composites. Journal of Materials Science, 40(17), pp. 4585-4592.

Tolêdo Filho et al. 2000. Durability of alkali-sensitive sisal and coconut fibres in cement mortar composites. Cement and Concrete Composites, 22(2), pp. 127-143.

Wang and Qiao. 2019. Coupled effect of cement-to-tailings ratio and solid content on the early age strength of cemented coarse tailings backfill. Geotechnical and Geological Engineering, 37(4), pp. $2425-2435$.

Weaver and Luka. 1970. Laboratory studies of cement-stabilized mine tailings. Canadian Mining and Metallurgical Bulletin, 63(701), pp. 988.

Yilmaz et al. 2015. Curing time effect on consolidation behaviour of cemented paste backfill containing different cement types and contents. Construction and Building Materials, 75. pp. 99-111. 